\title{
AVALIAÇÃO DO DESEMPENHO PROFISSIONAL E ORGANIZACIONAL DOS PARTICIPANTES DO EMPRETEC NO MUNICÍPIO DE ITABAIANA/SE
}

Hiago Da Silva Santos ${ }^{1}$

Márcio Nannini Da Silva Florêncio ${ }^{2}$

Maria Andréa Rocha Escobar²

${ }^{1}$ Universidade Federal de Sergipe / Campus Professor Alberto Carvalho - Itabaiana/SE

${ }^{2}$ Campus Professor Alberto Carvalho (Itabaiana) / Universidade Federal de Sergipe 


\section{AVALIAÇÃO DO DESEMPENHO PROFISSIONAL E ORGANIZACIONAL DOS PARTICIPANTES DO EMPRETEC NO MUNICÍPIO DE ITABAIANA/SE}

\section{RESUMO}

Este artigo tem como objetivo avaliar os impactos da metodologia para capacitação de empreendedores, EMPRETEC, em relação ao seu perfil profissional e o desempenho de seus negócios, a partir das Características do Comportamento Empreendedor de McClelland (1961). Para atingir o objetivo da pesquisa, optou-se pela abordagem quantitativa, com caráter descritivo através de um levantamento (survey). A coleta dos dados foi feita por meio de um questionário, aplicado in loco a 80 empretecos que participaram do programa de treinamento. Os resultados apontaram que tal metodologia exerceu impacto positivo na vida profissional dos participantes e no desempenho de seus empreendimentos. Constatou-se que os participantes passaram a utilizar os conhecimentos aprendidos, atuando de forma empreendedora, mais motivados em relação ao potencial de realização e planejando mais as atividades do negócio, conseguindo aumentar as vendas e as receitas, reduzir custos e possibilitando ainda, a expansão de seus negócios.

Palavras-chave: Empretec. Competências empreendedoras. Desempenho organizacional. Desempenho profissional.

\section{INTRODUÇÃO}

O empreendedor desempenha importante papel na economia, visto que, é um agente de mudança e propulsor do desenvolvimento econômico, criador de empresas e gerador de emprego e renda, diminui sua relação de dependência com o governo e fortalece a economia de um país. No entanto, com as altas taxas de mortalidade das empresas, exige-se que o empreendedor busque alternativas para sua sobrevivência de forma que sua gestão se torne mais profissional. Assim, o empreendedor manifesta diversas características que o distingue dos demais indivíduos na sociedade (CLEMENTE e ALMEIDA, 2013; MONTEIRO, 2014; LORENTZ, 2015;).

Segundo os estudos de McClelland (1961) da Universidade de Harvard, com apoio da Organização das Nações Unidas (ONU), o ser humano é caracterizado por sua motivação e é orientado por um fator intrínseco relacionado à realização de algo difícil e de valor social que pode ser chamado de necessidade de autorrealização, capaz de conduzir a sociedade e a economia. Gomes, Lima e Cappelle (2013) afirmam que esta necessidade é mais pertinente ao empreendedor que aos demais indivíduos.

McClelland (1961) dividiu essa necessidade em três conjuntos - de realização, afiliação/planejamento e poder - que contêm um total de dez características comportamentais que determinam o sucesso ou fracasso do empreendedor que são: busca de oportunidade e iniciativa, correr riscos calculados, persistência, exigência de qualidade e eficiência, 
comprometimento, busca de informações, estabelecimento de metas, planejamento e monitoramento sistemáticos, persuasão e redes de contato, independência e autoconfiança.

O Autor descobriu ainda, que é possível desenvolver a realização como motivação do comportamento empreendedor através de treinamento, foi assim que surgiu a metodologia de capacitação para empreendedores chamada de Empretec, com o objetivo de identificar e fortalecer as características do comportamento empreendedor, fundamentais para o progresso de novos negócios.

Segundo dados da UNCTAD (2018), um dos principais motivos para que se começasse a pensar no desenvolvimento desse treinamento foram as dificuldades que as empresas tinham em sobreviver no mercado competitivo e de conseguir bom desempenho econômico. De acordo com os dados do relatório do Sebrae (2018) uma em cada 4 empresas registradas com CNPJ fecha antes de completar 2 anos no mercado. A causa da mortalidade de empresas jovens pode ser atribuída a três principais fatores: planejamento prévio, gestão empresarial e o comportamento empreendedor.

A pesquisa do Sebrae (2017) realizada no ano de 2014 com 1.829 empreendedores mostrou que, em relação ao planejamento prévio: 55\% não elaboraram plano de negócios, $38 \%$ não identificaram necessidades do mercado, $46 \%$ não sabiam os hábitos de consumo dos clientes, 33\% não tinham informações sobre fornecedores e 38\% não sabiam o número de concorrentes que tinham.

A pesquisa também analisou a gestão empresarial e o comportamento empreendedor, onde foram entrevistados 1.732 empreendedores dos quais: $38 \%$ possuíam produtos e serviços diferenciados, $23 \%$ tinham preços competitivos, $20 \%$ desenvolviam propagandas de divulgação e $7 \%$ facilitaram a forma de pagamento a prazo; $59 \%$ buscavam informações, $62 \%$ planejavam e monitoravam etapas, $67 \%$ estabeleciam objetivos e metas, $54 \%$ enfrentavam "riscos moderados" e $89 \%$ seguiam os objetivos.

Diante disso, o presente estudou buscou avaliar os impactos da metodologia para capacitação de empreendedores, EMPRETEC, no perfil profissional e no desempenho do negócio, dos participantes residentes em Itabaiana-SE. Neste contexto a questão problema que esta pesquisa busca responder é: O programa de capacitação de empreendedores, EMPRETEC, exerce influência no desempenho profissional e o desempenho organizacional dos participantes do seminário na cidade de Itabaiana?

\section{REFERENCIAL TEÓRICO}

\subsection{Da teoria das necessidades de McClelland ao desenvolvimento de uma metodologia}

Segundo Costa (2015), durante a década de 60 o Programa das Nações Unidas para o Desenvolvimento (PNUD) o qual trabalha pelo desenvolvimento humano e combate à pobreza, constituiu um grupo de trabalho empenhado no fortalecimento das economias dos países em emergentes. A intenção do programa, era implementar ações para o incentivo ao surgimento de novos negócios, que se concentraram em três ações: acesso a crédito a juros atraentes, o melhoramento das capacidades técnicas dos candidatos e o reconhecimento dos comportamentos e iniciativas que possuíam os empreendedores de sucesso, sendo esta última a que mais se destacou. 
Para Krüger; Pinheiro e Minello (2017) o destaque para ações voltadas ao desenvolvimento do comportamento empreendedor se deu devido à fácil abordagem que apresentara McClelland em sua teoria motivacional, considerada ainda hoje uma das teorias mais complexas e importantes dentre as teorias do comportamento humano, pela sua capacidade de explicar a motivação do indivíduo a partir da satisfação de suas necessidades.

A partir disso, a Conferência das Nações Unidas para o Comércio e o Desenvolvimento (UNCTAD) passou a prospectar as experiências empreendedoras bem-sucedidas a partir dos estudos do psicólogo David McClelland da Universidade de Harvard, com cerca de 400 casos de sucesso que passaram a ser aplicados no treinamento de natureza comportamental chamado de Treinamento de Motivação para a Realização (TMR), para a capacitação de empreendedores e empresários, executado em mais de 40 países até o final dos anos 70 (KRÜGER; PINHEIRO e MINELLO, 2017).

Essa extensa pesquisa em países de culturas e realidades econômicas diferentes ajudou a responder às críticas de muitos pesquisadores quanto à falta de amostras que apresentassem análise intercultura e interracial utilizando-se metodologias de mensuração de competências para estudo das características dos empreendedores (MORALES, 2004).

McClelland (1972) buscava identificar competências correlacionadas com a ação empreendedora de sucesso através da técnica projetiva Picture-Story Exercise, orientada para resolução de problemas que chamou de "Thematic Apperception Test" (T.A.T), desenvolvido por Murray (1938) onde o indivíduo examinava uma série de figuras com pessoas em situações ambíguas distribuídas em cartões aos quais deveria elaborar uma história a partir de cada uma das imagens.

O método revelou que os empresários bem-sucedidos possuíam um atributo psicológico dominante que ele chamou de "motivação da realização" e o dividiu em três grupos de características essenciais chamadas de necessidade: de realização ( $n$-Achievement), de autoridade e poder ( $n$-Power), e de afiliação (n-Affiliation), conforme é mostrado no Quadro 1 (McClelland (1972).

\section{Quadro 1: Caracterização das necessidades de poder, sucesso e afiliação.}

\section{PODER}

O empreendedor se mobiliza como e quando quer, persuadindo, influenciando ou argumentando. Age ativamente nas decisões e políticas de suas organizações, equilibrando a relação pessoal dominadora e a liderança socializadora, revezando entre um aspecto e outro quando necessário.

\section{REALIZAÇÃO}

É o que leva os empreendedores a agir a partir de padrões de excelência com criatividade e inovação, buscando êxito em tudo o que fazem. Essa necessidade nutre-os de autoconfiança, deixando-os mais seguros ao assumir grandes responsabilidades, realizar suas metas e assumir riscos, desde que moderados e baseados em planejamento, com a finalidade de minimizá-los.

\section{AFILIAÇÃO/PLANEJAMENTO}

O empreendedor se preocupa mais com os indivíduos que com ele mesmo, com as tarefas e a produção, sem desejo de destaque, desempenhando melhor sua função em forma de cooperação. Demonstra a necessidade de estabelecer ou manter relações emocionais com as pessoas, resultando da capacidade de planejamento para soluções de dificuldades a partir de tais relações.

Fonte: McClelland (1972). 
Deste modo, existe uma presunção subjacente ao teste de que os relatos inventivos dos participantes revelam seus sonhos, fantasias e aspirações. Para tanto, os conteúdos das histórias foram analisados por meio de sistemas de codificação que possibilitaram pontuá-los dentro desses três motivos (HEYNS; VEROFF e ATKINSON, 1958; MCCLELLAND ET AL., 1953; VEROFF, 1992; WINTER, 1992).

Após identificadas as três necessidades, McClelland deu início em 1982, a um projeto para aperfeiçoamento da metodologia TMR através de estudos mais amplos a respeito do comportamento com a finalidade de encontrar meios de seleção e desenvolvimento de empreendedores mais eficazes.

Foi então que, a McBer e Company, empresa de consultoria de McClelland em parceria com a Agência para o Desenvolvimento Internacional das Nações Unidas (USAID) e a Management Systems International (MSI) iniciaram um novo projeto em 34 países, conseguindo identificar 20 características comportamentais comuns a empreendedores de sucesso (FIALHO; MINUZZI e VARGAS, 2016). Mas, uma rigorosa revisão da literatura realizada pela Heber and Company que acompanhava as pesquisas no Equador, Índia e Malawi permitiu que modificações no estudo continuassem sendo feitas, o que resultou entre os anos de 1985 e 1986 numa redução dessas características para dez (MSI, 1990).

Essa redução se deu através de práticas pedagógicas que fizeram com que algumas Características do Comportamento Empreendedor (CCE) fossem excluídas ou agrupados e outras, por serem ambíguas ou por terem sido mal interpretadas e mal utilizadas quando praticadas, foram eliminadas. Outras Características que podiam ser ensinadas também foram separadas das que não podiam (TORRES, 2018).

Uma nova formatação do modelo de exercícios do TMR foi apresentada em novos testes em campo nos Estados Unidos, Inglaterra, Quênia e Senegal. Passado o período de experiência, o modelo final de teste com as dez CCEs que o empreendedor deve possuir ou desenvolver foi aplicado no Malawi em 1986 (MSI, 1990).

Assim, McClelland finalmente apresentou as dez características comportamentais evidenciadas que o empreendedor deve ter, desenvolver ou aperfeiçoar, divididas dentro dos três grupos de necessidades: de realização, de afiliação/planejamento e de poder, conforme apresentado no Quadro 2.

Quadro 2: As 10 Características do Comportamento Empreendedor.

(continua)

CARACTERÍSTICAS COMPORTAMENTAIS EMPREENDEDORA (CCE)

CONJUNTO DE REALIZAÇÃO

\begin{tabular}{|l|l|}
\hline $\begin{array}{l}\text { Busca de } \\
\text { oportunidades e } \\
\text { iniciativa }\end{array}$ & $\begin{array}{l}\text { Faz as coisas antes de solicitado ou antes de forçado pelas circunstâncias; age para expandir } \\
\text { o negócio a novas áreas, produtos ou serviços; aproveita oportunidades fora do comum para } \\
\text { começar um negócio, obter financiamento, equipamentos, local de trabalho ou assistência. }\end{array}$ \\
\hline Persistência & $\begin{array}{l}\text { Age diante de um obstáculo significativo; age repetidamente ou muda de estratégia a fim } \\
\text { de enfrentar um desafio ou superar um obstáculo; faz um sacrifício pessoal ou despende } \\
\text { um esforço extraordinário para completar uma tarefa. }\end{array}$ \\
\hline $\begin{array}{l}\text { Correr riscos } \\
\text { calculados }\end{array}$ & $\begin{array}{l}\text { Avalia alternativas e calcula riscos deliberadamente; age para reduzir os riscos ou controlar } \\
\text { os resultados; coloca-se em situações que implicam desafios ou riscos moderados. }\end{array}$ \\
\hline $\begin{array}{l}\text { Exigência de } \\
\text { qualidade e } \\
\text { eficiência }\end{array}$ & $\begin{array}{l}\text { Encontra maneiras de fazer as coisas melhor, mais rápido ou mais barato; age de maneira a } \\
\text { fazer coisas que satisfaçam ou excedam padrões de excelência; desenvolve ou utiliza } \\
\text { procedimentos para assegurar que o trabalho seja terminado a tempo ou que atenda a } \\
\text { padrões de qualidade previamente combinados. }\end{array}$ \\
\hline Comprometimento & $\begin{array}{l}\text { Assume responsabilidade pessoal por solucionar problemas que possam prejudicar a } \\
\text { conclusão de um trabalho nas condições estipuladas; colabora com seus empregados ou } \\
\text { coloca-se no lugar deles, se necessário, para terminar uma tarefa; esforça-se em manter os } \\
\text { clientes satisfeitos e coloca a boa vontade a longo prazo acima do lucro a curto prazo. }\end{array}$ \\
\hline
\end{tabular}

DOI: $10.14211 /$ xi-egepe-118140 


\begin{tabular}{|l|l|}
\hline \multicolumn{2}{|c|}{ CONJUNTO DE AFILIAÇÃO/ PLANEJAMENTO } \\
\hline $\begin{array}{l}\text { Busca de } \\
\text { informações }\end{array}$ & $\begin{array}{l}\text { Dedica-se pessoalmente a obter informações de clientes, fornecedores ou concorrentes; } \\
\text { investiga pessoalmente como fabricar um produto ou fornecer um serviço; consulta } \\
\text { especialistas para obter assistência técnica ou comercial. }\end{array}$ \\
\hline $\begin{array}{l}\text { Estabelecimento } \\
\text { de metas }\end{array}$ & $\begin{array}{l}\text { Estabelece metas e objetivos que são desafiantes e que têm significado pessoal; tem visão } \\
\text { de longo prazo, clara e específica; estabelece objetivos de curto prazo mensuráveis. }\end{array}$ \\
\hline $\begin{array}{l}\text { Planejamento e } \\
\text { monitoramento }\end{array}$ & $\begin{array}{l}\text { Planeja dividindo tarefas de grande porte em subtarefas com prazos definidos; } \\
\text { constantemente revisa seus planos levando em conta os resultados obtidos e mudanças } \\
\text { circunstanciais; mantém registros financeiros e utiliza-os para tomar decisões. }\end{array}$ \\
\hline $\begin{array}{l}\text { Independência e } \\
\text { autoconfiança }\end{array}$ & $\begin{array}{l}\text { Busca autonomia em relação a normas e controles de outros; mantém seu ponto de vista } \\
\text { mesmo diante da oposição ou de resultados inicialmente desanimadores; expressa } \\
\text { confiança na sua própria capacidade de completar uma tarefa difícil ou de enfrentar um } \\
\text { desafio. }\end{array}$ \\
\hline $\begin{array}{l}\text { Persuasão e rede } \\
\text { de contatos }\end{array}$ & $\begin{array}{l}\text { Utiliza estratégias deliberadas para influenciar ou persuadir os outros; utiliza pessoas-chave } \\
\text { como agentes para atingir seus próprios objetivos; age para desenvolver e manter relações } \\
\text { comerciais. }\end{array}$ \\
\hline
\end{tabular}

Fonte: McClelland (1987).

Segundo Barlach (2014), McClelland estudou ainda, culturas primitivas onde havia atividade econômica, buscando compreender se em seus contos folclóricos havia registros de empreendedorismo. Ele investigou ainda, histórias contadas a alunos em fase de alfabetização e as comparou ao índice de n-achievement em diferentes períodos de desenvolvimento econômico. Relacionou este mesmo índice ao comportamento parental e verificou que a escolha pelo empreendedorismo era influenciada pela independência, sobretudo, das mães no convívio familiar. Ele também verificou na literatura se os relatos de empreendedorismo eram mais frequentes antes de períodos de grande desenvolvimento econômico.

$\mathrm{O}$ autor conclui afirmando que para McClelland, o empreendedor é dotado da mesma estrutura motivacional daqueles que buscam as condições de independência que o auto emprego proporciona. Ele é o resultado do desenvolvimento cognitivo de seu aprendizado social, provenientes de suas experiências ao decorrer da história.

Dolabela (1999, p.46) corrobora com esta ideia ao afirmar que tão frequente se estabelece padrões internos quão alto for o nível cultural e, aqueles indivíduos que possuem noção interna de sucesso são mais suscetíveis a alcançar a autorrealização. Portanto, "uma sociedade que tenha um nível geralmente elevado de realização produzirá um maior número de empresários ativos, os quais, por sua vez, darão origem a um desenvolvimento econômico mais rápido" (MCCLELLAND, 1967, p. 95).

\subsection{O Programa Empretec no mundo e no Brasil}

McClelland e Winter (1971) afirmam que os estudos citados anteriormente foram o alicerce para o Programa das Nações Unidas para o Desenvolvimento (PNUD), voltado à capacitação de empreendedores, que só foi lançado oficialmente como treinamento no ano de 1988 com o nome de Empretec. O intuito do programa era desenvolver e/ou aprimorar as CCEs, determinando o sucesso empreendedor, favorecendo a competitividade e permanência no mercado.

A partir da definição da metodologia Empretec com o isolamento das CCEs como seminário, sua aplicação ampliou-se inicialmente a um total de 16 países, incluindo o Brasil. A elaboração e implementação da metodologia se deu pela vice-presidente do MSI, a mexicana 
naturalizada americana Marina Fanning que apresentou o programa do curso para as Nações Unidas que o adotou mundialmente (UNCTAD, 2018).

Na Argentina, onde foi lançado o programa, em 1988, o nome Empretec foi dado por ser inicialmente direcionado a empresas de tecnologia, concretizando o nome até os dias de hoje. Atualmente o seminário acontece em 39 países, tendo treinado até então, cerca de 400 mil pessoas. Seu maior centro nacional implantado é o Brasil, onde é aplicado por intermédio do SEBRAE (UNCTAD, 2018).

O Empretec chega ao Brasil um ano após seu lançamento na Argentina, licenciado pelo Banco do Estado do Rio Grande do Sul (Banrisul), sendo aplicado a candidatos de programas de crédito para projetos tecnológicos. Só em 1993 o Sebrae passa a ser o único licenciado a aplicar a metodologia no país sob a chancela do PNUD, estendendo-a a todas os estados a partir do ano 2000 (UNCTAD, 2018).

Segundo relatório da UNCTAD (2018), nos 25 anos de Empretec no Brasil, já foram treinados mais de 260.000 (cerca de $65 \%$ do total de participantes em todo o mundo) empreendedores nas mais de 11.000 oficinas realizadas.

A qualidade dos profissionais também é um fator a ser considerado, uma vez que conta com administradores, psicólogos e empresários como facilitadores, que recebem treinamento por três anos para que dominem totalmente a metodologia da ONU. Outros fatores preponderantes foram, as facilidades tributarias e de negócios que vieram com a Lei das Micro e Pequenas Empresas de 2006 e o Simples Nacional, fazendo com que muitos brasileiros buscassem empreender mais e procurassem o Sebrae para sua orientação (SEBRAE, 2013).

Segundo o Empretec Annual Report (2015), o principal produto do programa Empretec é o Entrepreneurship Training Workshop (ETW) que promove uma metodologia de mudança de comportamento, auxiliando os empreendedores a colocarem suas ideias em prática, o que ajuda no desenvolvimento de suas empresas.

Assim, esse modelo de apresentação padronizado é utilizado para avaliar as forças e fraquezas percebidas pelos empreendedores e as dinâmicas permitem que o empresário compreenda e aplique rapidamente seus ensinamentos (SEBRAE, 2013), cujo objetivo é, de acordo com Torres (2018), fomentar o empreendedorismo aumentando a capacidade produtiva e possibilitando a competitividade internacional das Micro e Pequenas Empresas (MPE) dos países em desenvolvimento.

Os principais objetivos do EMPRETEC são:

\footnotetext{
Mostrar a diferença entre operar um negócio (Empresário) e gerir um empreendimento orientado para crescimento e resultados (Empreendedor); promover, entre seus participantes, mudanças comportamentais, através de diversas dinâmicas e exercícios vivenciais, de modo a que essas mudanças levem os participantes a obter melhores resultados em seus empreendimentos" (TORRES, 2018, p. 29).
}

Em Sergipe, o Empretec foi implantado em 2001, sendo o último estado a aderir ao programa com interiorização somente em 2002 no município de Lagarto, na região centro Sul do estado. Durante 17 anos de realização no estado já foram capacitados cerca 3 mil empresários e futuros empreendedores (SEBRAE, 2018).

Segundo dados do Sebrae (2018), no ano de 2017, a coordenação resolveu fazer algumas mudanças na metodologia e deixar o seminário mais moderno, utilizando ferramentas de modelagem de negócios como Design Thinking, Modelos de Negócios (Canvas) e temas como Sustentabilidade, além de dois workshops que acontecem 21 dias após o seminário. 
Desta forma acontece também na cidade de Itabaiana na região agreste de Sergipe, onde este programa de imersão profissional para empreendedores é aplicado pelo escritório regional do Sebrae que o apresenta na modalidade de seminário, segundo suas diretrizes, sendo realizado em média uma vez ao ano. O seminário é desenvolvido ao longo de seis dias, de segunda a sábado com atividades teóricas e práticas desenvolvidas em sala como, jogos, e desafios e fora de sala como, pesquisas de mercado e desenvolvimento de produtos/serviços.

Nesta seção, busca-se conhecer outras pesquisas desenvolvidas no Brasil que também abordam a temática deste estudo. Para isso, foram identificados diversos trabalhos sob pontos de vista distintos que permitiram o autor deste trabalho abordar esse tema, conforme já apresentado em capítulos anteriores.

Gomes (2014) buscou analisar a eficácia do Programa Empretec sobre o comportamento profissional e pessoal dos participantes na cidade de Angra dos Reis no Rio de Janeiro. A pesquisa teve abordagens quantitativa e qualitativa, com a coleta de dados realizada por meio de um questionário aplicado via telefone a 49 Empretecos do ano de 2004. Todas as CCEs analisadas obtiveram resultados a partir de $62 \%$ de melhoria segundo respostas dos participantes, sendo que, $80 \%$ deles já eram empresários, $10 \%$ passaram a ser e os outros $10 \%$ continuam não sendo; $82 \%$ criaram novos produtos/serviços; $82 \%$ aumentaram a rede de contatos; 94\% afirmaram que sua capacidade de reconhecer oportunidades também aumentou; para $78 \%$ os resultados financeiros melhoraram, para $20 \%$ não houve alteração e para $2 \%$ a situação piorou.

Fonseca e Muylder (2010) buscaram elementos que evidenciassem a evolução no perfil dos 31 empretecos da cidade de Manhuaçu em Minas Gerais, no ano de 2008. A partir de uma abordagem exploratória quantitativa, foi aplicado o questionário McClelland aos participantes. $\mathrm{O}$ estudo verificou que todas as dez CCEs obtiveram mais de 15 pontos, considerando-se um bom patamar, segundo os requisitos preconizados nos estudos de McClelland, verificando-se a melhoria do comportamento empreendedor. As CCEs mais evidentes foram Comprometimento, Exigência de Qualidade e Eficiência, e Busca de Oportunidade e Iniciativa.

Já Costa (2015) desenvolveu uma pesquisa com o objetivo de analisar o valor dos treinamentos empresariais como ferramentas de formação empreendedora para abertura de micro e pequenas empresas e para o bom desempenho empresarial. $\mathrm{O}$ tipo de pesquisa desenvolvida foi exploratório e descritivo e os dados foram obtidos com um questionário onde foi comparado o antes e o depois do desempenho de 72 participantes do Empretec durante o ano de 2010, na cidade de Macapá no estado do Amapá.

$\mathrm{O}$ estudo mostrou que o número de empresas abertas mais que dobrou se comparado com o número de empresas que existia antes do treinamento. A porcentagem de participantes que não possuía empresa antes do treinamento era de 57\%, destes, os que não tinham a intenção de empreender era de $43,10 \%$, após o treinamento, $100 \%$ dos participantes passaram a ter a intenção de empreender e houve um aumento de 54,1\% na natalidade de empresas; depois do treinamento o percentual de participantes que possuíam empresas informais caiu de $27,8 \%$ para 5,6\%; o número de firmas com CNPJ passou de 15,3\% para 91,7\% entre os participantes; o aumento do número de empresas abertas formais foi de $76,4 \%$, ao passo que as novas empresas que surgiam já nasceram na formalidade. Por fim, foram abertas 16,5 vezes mais empresas formais do que as informais (COSTA, 2015).

Torres (2018) buscou avaliar o impacto do Empretec sobre o comportamento empreendedor e nos resultados dos empreendimentos dos participantes na cidade de São Paulo, após a mudança que ocorreu na metodologia a partir do ano de 2011. Para isso, a pesquisa teve 
abordagem exploratória e qualitativa com questionário aplicado on-line a 265 participantes do seminário. Contudo, 133 respondentes participaram do seminário no ano de 2016, sendo que a metodologia já havia mudado novamente e era apresentada não mais em 9 dias, mas em 6. Assim, ele conseguiu avaliar a situação dos empretecos em relação a 2 momentos distintos.

Torres (2018) conseguiu verificar que 60\% das empresas participantes era composta por microempresários com faturamento bruto mensal entre $\mathrm{R} \$ 60$ e $\mathrm{R} \$ 360$ mil; o número de empresas sem funcionários caiu de $30 \%$ para $8 \%$; evidenciou-se a presença de todas as CCEs, sendo que as praticadas com mais intensidade foram: Comprometimento, Independência e Autoconfiança e Busca de Informação. Quanto às práticas de gestão, 77,1\% deles aproveitaram as oportunidades que surgiram; $55,7 \%$ dedica de 10 a 12 horas de trabalho; $65,5 \%$ estabeleceram objetivos em função do que desejavam para o negócio e; $79 \%$ estabeleceram metas para os 5 anos seguintes, dentre outras condições analisadas.

A pesquisa de Coelho; Loureiro e Moreira (2018) buscou avaliar o impacto do Empretec na vida profissional dos participantes da cidade de Recife. Para tanto, a metodologia utilizada foi a pesquisa quantitativa, contando com 66 Empretecos que se formaram entre os anos de 2012 e 2013. Foi possível demonstrar que o programa exerceu impacto na vida profissional dos Empretecos, motivando-os a abrirem empresas ou expandi-las e a mudarem de ramo de atuação. Evidenciou-se que a metodologia utilizada incorreu em redução na mortalidade das empresas por permitir melhoria nas competências administrativas, inovadoras e de planejamento e na identificação de oportunidade, favorecendo maior rentabilidade e melhoria na qualidade dos produtos e serviços.

\section{METODOLOGIA}

De natureza empírica, este estudo se caracteriza como sendo caracterizada por uma abordagem quantitativa e de caráter descritivo e exploratório. Os dados foram gerados com 80 empreendedores/empresários que já participaram do seminário de capacitação empreendedora Empretec na cidade de Itabaiana.

Como técnica para coleta dos dados, utilizou-se de uma survey ou levantamento, por meio de um questionário validado por Alvim (2008), a partir das dez Características do Comportamento Empreendedor de McClelland (1985), o qual foi aplicado de abril e julho de 2019.

O instrumento de coleta de dados estava estruturado com perguntas fechadas em dois blocos: O primeiro, mensurou-se o quanto o curso Empretec foi capaz de contribuir para a mudança no desempenho profissional do participante, verificando-se qual sua percepção quanto a dois momentos, um anterior ao curso e outro com considerações a respeito do momento posterior à sua participação. As competências empreendedoras analisadas no segundo bloco do questionário trazem as 10 CCEs que são, do conjunto de realização: busca de oportunidade e iniciativa; persistência, correr riscos calculados, exigência de qualidade e eficiência, comprometimento; do conjunto de afiliação/planejamento: busca de informações, estabelecimento de metas, planejamento e monitoramento sistemático; do conjunto de poder: independência e autoconfiança, persuasão e rede de contatos. Cada um dos itens devia ser marcado utilizando-se uma escala intervalar de cinco pontos, (1) nunca, (2) raras vezes, (3) algumas vezes, (4) quase sempre e (5) sempre. Assim, sendo 3 o valor médio, a caracterização da competência do empreendedor se dá com resultados acima da média (BEHLING, 2015). 
O segundo bloco do questionário, traz asseverações referentes à utilização dos aprendizados do Empretec no negócio e o impacto que isso proporcionou ao seu desempenho. As respostas também variavam dentro de uma escala Likert de 5 pontos.

A etapa de tratamento dos dados é o procedimento que dá sentido aos dados que foram coletados via questionário. Para esta análise, os dados foram organizados, codificados e processados com o auxílio de uma planilha Excel®, a partir da qual, foram confeccionados gráficos e tabelas para compor a descrição da amostra. Posteriormente as informações foram importadas para o software SPSS 20, para realização dos testes de Análise de Estatística Descritiva, onde foram obtidas as médias, as variâncias e desvios padrão das amostras que serviram para compor os resultados desta pesquisa.

\section{RESULTADOS}

\subsection{Avaliação do impacto do Empretec sobre o desempenho profissional}

Analisando as opiniões respondentes, quanto o grau de competências empreendedoras antes da participação no EMPRETEC. A Tabela 1 apresenta os dados relativos às médias encontradas na avaliação anterior à participação no programa de treinamento - Empretec.

Tabela 1: Médias gerais por CCE - momento anterior ao Empretec.

(continua)

\begin{tabular}{|c|c|c|c|}
\hline 1. Busca de oportunidades e iniciativa (BOI) & Média & DP & MG \\
\hline $\begin{array}{l}\text { Reconheço fontes de oportunidades e atuo sobre elas para abrir um novo negócio ou } \\
\text { oferecer um novo produto/serviço. }\end{array}$ & 2,36 & 1,12 & \multirow{3}{*}{2,61} \\
\hline Eu procuro observar no mercado oportunidades existentes. & 2,73 & 1,16 & \\
\hline Estou atendo às oportunidades de mercado. & 2,73 & 1,1 & \\
\hline 2. Persistência (PER) & Média & DP & MG \\
\hline $\begin{array}{l}\text { Persisto em ações para atingir objetivos previamente estabelecidos mesmo a custo de } \\
\text { sacrifícios pessoais. }\end{array}$ & 2,65 & 1,24 & \multirow[t]{2}{*}{2,66} \\
\hline Aceito mudar de estratégia, para atingir objetivos previamente definidos. & 2,66 & 1,18 & \\
\hline 3. Correr riscos calculados (CRC) & Média & DP & MG \\
\hline Analiso as informações do mercado antes de tomar decisões que de riscos. & 2,38 & 1,19 & 2,38 \\
\hline 4. Exigência de qualidade e eficiência (EQE) & Média & DP & MG \\
\hline $\begin{array}{l}\text { Aprimoro a qualidade dos produtos/serviços para atender as exigências do cliente da } \\
\text { forma mais rápida e barata possível. }\end{array}$ & 2,81 & 1,21 & \multirow{2}{*}{2,73} \\
\hline $\begin{array}{l}\text { Analiso a relação entre qualidade, custo e tempo antes de propor um produto/serviço } \\
\text { novo ou melhoria de um produto/serviço já existente. }\end{array}$ & 2,65 & 1,24 & \\
\hline 5. Comprometimento (COM) & Média & DP & MG \\
\hline $\begin{array}{l}\text { Estimulo a participação da equipe de trabalho na busca pela solução de problemas para } \\
\text { atender necessidades dos clientes. }\end{array}$ & 2,54 & 1,09 & \multirow[t]{2}{*}{2,70} \\
\hline Estimulo o espírito de equipe entre os indivíduos com diferentes funções. & 2,86 & 1,27 & \\
\hline 6. Busca de informações (BDI) & Média & DP & MG \\
\hline Elaboro roteiros para coletar e organizar informações sobre o mercado. & 1,98 & 1,11 & \multirow{3}{*}{2,09} \\
\hline $\begin{array}{l}\text { Entrevisto pessoalmente clientes, fornecedores e/ou concorrentes antes de tomar } \\
\text { decisões que envolvam riscos. }\end{array}$ & 2,00 & 1,09 & \\
\hline $\begin{array}{l}\text { Consulto especialistas antes de tomar uma decisão que envolva conhecimentos técnicos } \\
\text { sobre um determinado assunto. }\end{array}$ & 2,3 & 1,15 & \\
\hline 7. Estabelecimento de metas (EDM) & Média & DP & MG \\
\hline $\begin{array}{l}\text { Estabeleço metas PROFISSIONAIS específicas, mensuráveis, alcançáveis, relevantes e } \\
\text { com tempo definido. }\end{array}$ & 1,90 & 0,88 & 2,02 \\
\hline
\end{tabular}




\begin{tabular}{|c|c|c|c|}
\hline $\begin{array}{l}\text { Estabeleço metas PESSOAIS específicas, mensuráveis, alcançáveis, relevantes e com } \\
\text { tempo definido. }\end{array}$ & 2,13 & 1,07 & \\
\hline Realizo projeções para o futuro do negócio e/ou futuro profissional. & 2,04 & 0,93 & \\
\hline 8. Planejamento e monitoramento (PMS) & Média & DP & MG \\
\hline $\begin{array}{l}\text { Planejo as atividades do meu negócio subdividindo tarefas de grande porte em subtarefas } \\
\text { com prazos definidos. }\end{array}$ & 2,15 & 0,99 & \multirow{3}{*}{2,19} \\
\hline $\begin{array}{l}\text { Realizo compras, vendas, investimentos e/ou outras transações financeiras levando em } \\
\text { conta o meu planejamento financeiro. }\end{array}$ & 2,48 & 1,11 & \\
\hline Elaboro plano de negócios a partir das informações e materiais do curso. & 1,93 & 1,03 & \\
\hline 9. Independência e autoconfiança (IAC) & Média & DP & MG \\
\hline Identifico com clareza os pontos fortes do meu comportamento empreendedor. & 2,46 & 1,23 & \multirow{4}{*}{2,50} \\
\hline Identifico com clareza os pontos fracos do meu comportamento empreendedor. & 2,29 & 1,15 & \\
\hline $\begin{array}{l}\text { Tomo decisões que envolvam sócios ou equipe de trabalho dando prioridade às questões } \\
\text { profissionais em detrimento das questões afetivas. }\end{array}$ & 2,49 & 1,23 & \\
\hline Atribuo a mim mesmo (a) as causas dos meus sucessos e fracassos. & 2,74 & 1,38 & \\
\hline 10. Persuasão e rede de contatos (PRC) & Média & DP & MG \\
\hline $\begin{array}{l}\text { Exponho com segurança meus projetos ou produtos diante de examinadores, clientes ou } \\
\text { especialistas. }\end{array}$ & 2,43 & 1,16 & \multirow{3}{*}{2,60} \\
\hline Realizo negociações de maneira objetiva, transparente e sustentável. & 2,71 & 1,27 & \\
\hline $\begin{array}{l}\text { Convenço colaboradores, colegas de trabalho, sócios, parceiros e/ou fornecedores a se } \\
\text { engajarem nos meus planos empresariais e/ou profissionais. }\end{array}$ & 2,65 & 1,22 & \\
\hline
\end{tabular}

Fonte: dados da pesquisa (2019).

Nota: $\mathrm{DP}=$ Desvio padrão. $\mathrm{MG}=$ Média geral

Os resultados mostram que antes da participação no Empretec, não há evidências de que os respondentes possuíam as competências empreendedoras uma vez que, todas as médias apresentam resultados inferiores a três, ou seja, houve discordância em relação as asseverações apontadas.

A seguir, são apresentados os resultados das respostas com as considerações dos empretecos para o momento após a participação no seminário, conforme a Tabela 2.

Tabela 2: Médias gerais por $\mathrm{CCE}$ - momento posterior ao Empretec.

\begin{tabular}{|c|c|c|c|}
\hline 1. Busca de oportunidades e iniciativa (BOI) & Média & DP & MG \\
\hline $\begin{array}{l}\text { Reconheço fontes de oportunidades e atuo sobre elas para abrir um novo negócio ou } \\
\text { oferecer um novo produto/serviço. }\end{array}$ & 4,13 & 0,79 & \multirow{3}{*}{4,21} \\
\hline Eu procuro observar no mercado oportunidades existentes. & 4,26 & 0,81 & \\
\hline Estou atendo às oportunidades de mercado. & 4,25 & 0,79 & \\
\hline 2. Persistência (PER) & Média & DP & MG \\
\hline $\begin{array}{l}\text { Persisto em ações para atingir objetivos previamente estabelecidos mesmo a custo de } \\
\text { sacrifícios pessoais. }\end{array}$ & 4,13 & 1,01 & \multirow[t]{2}{*}{4,66} \\
\hline Aceito mudar de estratégia, para atingir objetivos previamente definidos. & 4,2 & 0,79 & \\
\hline culados (CRC) & Média & $\mathbf{D P}$ & MG \\
\hline Analiso as informações do mercado antes de tomar decisões qu & 4,05 & 0,087 & 4,05 \\
\hline 4. Exigência de qualidade e eficiência (EQE) & Média & DP & MG \\
\hline $\begin{array}{l}\text { Aprimoro a qualidade dos produtos/serviços para atender as exigências do cliente da } \\
\text { forma mais rápida e barata possível. }\end{array}$ & 4,23 & 0,89 & \multirow{2}{*}{4,24} \\
\hline $\begin{array}{l}\text { Analiso a relação entre qualidade, custo e tempo antes de propor um produto/serviço } \\
\text { novo ou melhoria de um produto/serviço já existente. }\end{array}$ & 4,25 & 0,75 & \\
\hline 5. Comprometimento (COM) & Média & DP & MG \\
\hline $\begin{array}{l}\text { Estimulo a participação da equipe de trabalho na busca pela solução de problemas } \\
\text { para atender necessidades dos clientes. }\end{array}$ & 4,39 & 0,65 & \multirow[t]{2}{*}{4,37} \\
\hline Estimulo o espírito de equipe entre os indivíduos com diferentes funções. & 4,34 & 0,78 & \\
\hline
\end{tabular}




\begin{tabular}{|c|c|c|c|}
\hline 6. Busca de informações (BDI) & Média & $\mathbf{D P}$ & MG \\
\hline Elaboro roteiros para coletar e organizar informações sobre o mercado. & 3,58 & 1,05 & \multirow{3}{*}{3,79} \\
\hline $\begin{array}{l}\text { Entrevisto pessoalmente clientes, fornecedores e/ou concorrentes antes de tomar } \\
\text { decisões que envolvam riscos. }\end{array}$ & 3,81 & 1,02 & \\
\hline $\begin{array}{l}\text { Consulto especialistas antes de tomar uma decisão que envolva conhecimentos } \\
\text { técnicos sobre um determinado assunto. }\end{array}$ & 3,99 & 1,07 & \\
\hline 7. Estabelecimento de metas (EDM) & Média & DP & MG \\
\hline $\begin{array}{l}\text { Estabeleço metas PROFISSIONAIS específicas, mensuráveis, alcançáveis, relevantes } \\
\text { e com tempo definido. }\end{array}$ & 3,85 & 0,86 & \multirow{3}{*}{3,92} \\
\hline $\begin{array}{l}\text { Estabeleço metas PESSOAIS específicas, mensuráveis, alcançáveis, relevantes e com } \\
\text { tempo definido. }\end{array}$ & 4,01 & 0,93 & \\
\hline Realizo projeções para o futuro do negócio e/ou futuro profissional. & 3,91 & 0,94 & \\
\hline 8. Planejamento e monitoramento (PMS) & Média & DP & MG \\
\hline $\begin{array}{l}\text { Planejo as atividades do meu negócio subdividindo tarefas de grande porte em } \\
\text { subtarefas com prazos definidos. }\end{array}$ & 3,85 & 1,04 & \multirow{3}{*}{3,80} \\
\hline $\begin{array}{l}\text { Realizo compras, vendas, investimentos e/ou outras transações financeiras levando } \\
\text { em conta o meu planejamento financeiro. }\end{array}$ & 4,05 & 0,81 & \\
\hline Elaboro plano de negócios a partir das informações e materiais do curso. & 3,5 & 1,09 & \\
\hline 9. Independência e autoconfiança (IAC) & Média & DP & MG \\
\hline Identifico com clareza os pontos fortes do meu comportamento empreendedor. & 4,04 & 0,92 & \multirow{4}{*}{4,13} \\
\hline Identifico com clareza os pontos fracos do meu comportamento empreendedor. & 4,05 & 0,91 & \\
\hline $\begin{array}{l}\text { Tomo decisões que envolvam sócios ou equipe de trabalho dando prioridade às } \\
\text { questões profissionais em detrimento das questões afetivas. }\end{array}$ & 4,05 & 0,93 & \\
\hline Atribuo a mim mesmo (a) as causas dos meus sucessos e fracassos. & 4,38 & 0,7 & \\
\hline 10. Persuasão e rede de contatos (PRC) & Média & DP & MG \\
\hline $\begin{array}{l}\text { Exponho com segurança meus projetos ou produtos diante de examinadores, clientes } \\
\text { ou especialistas. }\end{array}$ & 3,95 & 0,95 & \multirow{3}{*}{4,12} \\
\hline Realizo negociações de maneira objetiva, transparente e sustentável. & 4,31 & 0,74 & \\
\hline $\begin{array}{l}\text { Convenço colaboradores, colegas de trabalho, sócios, parceiros e/ou fornecedores a } \\
\text { se engajarem nos meus planos empresariais e/ou profissionais. }\end{array}$ & 4,09 & 0,83 & \\
\hline
\end{tabular}

Fonte: Dados da pesquisa (2019)

Observando a Tabela 2, pode-se inferir que após a participação no curso EMPRETEC, os inquiridos afirmaram que desenvolveram competências empreendedoras. Foi observado que as características persistência $(4,66)$, comprometimento $(4,37)$ e exigência de qualidade e eficiências $(4,24)$ apresentaram as maiores médias gerais. Por outro lado, busca de informações e planejamento e monitoramento obtiveram as menores médias, indicando que estas características necessitam de maior atenção.

\subsection{Avaliação do impacto do Empretec sobre o desempenho do negócio}

O segundo objetivo desta pesquisa foi avaliar o impacto do Empretec sobre o negócio do participante. Para tal, foi aplicado um questionário que indica o quanto os respondentes aplicam no negócio o que aprenderam no seminário e quanto isso influência nos resultados da empresa.

Conforme as médias das respostas (Tabela 3), pode-se inferir que, os participantes recordam bem dos conteúdos ensinados no Empretec e ainda os utilizam com frequência no trabalho/negócio, bem como as habilidades, conhecimentos e atitudes aprendidos que possibilitaram a eles cometer menos erros nas atividades relacionadas ao conteúdo do treinamento. 
Tabela 3: Média Geral por respostas - itens 1 a 3.

\begin{tabular}{|c|c|c|c|}
\hline $\mathbf{N}^{\mathbf{o}}$ & Item & Média & DP \\
\hline 1 & $\begin{array}{l}\text { Utilizo, com frequência, no meu trabalho e/ou negócio atual, o que foi } \\
\text { ensinado no EMPRETEC. }\end{array}$ & 3,48 & 0,87 \\
\hline 2 & $\begin{array}{l}\text { As habilidades, conhecimentos e atitudes que aprendi no EMPRETEC fizeram } \\
\text { com que eu cometesse menos erros, em meu trabalho e/ou negócio, em } \\
\text { atividades relacionadas ao conteúdo do treinamento. }\end{array}$ & 3,80 & 0,99 \\
\hline 3 & Recordo-me bem dos conteúdos ensinados no EMPRETEC. & 3,59 & 0,91 \\
\hline
\end{tabular}

Fonte: Dados da pesquisa (2019).

Verificou-se também que os respondentes tiveram mais motivação para o trabalho e/ou para gerir a empresa estando mais receptivos às mudanças que vierem a ocorrer e que, passaram a ter uma visão mais destemida do futuro considerando-se mais autoconfiantes em relação ao empreendedorismo, afirmando que atuam de forma mais empreendedora, não só no trabalho/negócio, mas em outras esferas da vida, conforme é apresentado na Tabela 4.

Tabela 4: Média Geral por respostas - itens 4 a 8.

\begin{tabular}{clcc}
\hline $\mathbf{N}^{\mathbf{0}}$ & \multicolumn{1}{c}{$\begin{array}{c}\text { Item } \\
\text { Considero que atuo de forma mais empreendedora não só nas práticas }\end{array}$} & Média & DP \\
$\mathbf{4}$ & $\begin{array}{l}\text { relacionadas ao meu trabalho atual e/ou negócio, mas também em outras esferas } \\
\text { da minha vida. }\end{array}$ & 4,08 & 0,78 \\
$\mathbf{5}$ & $\begin{array}{l}\text { Minha participação no EMPRETEC serviu para aumentar minha motivação } \\
\text { para o trabalho e/ou para gerir a empresa. }\end{array}$ & 4,34 & 0,75 \\
$\mathbf{6} \begin{array}{l}\text { Minha participação no EMPRETEC aumentou minha autoconfiança no meu } \\
\text { potencial de empreendedor. }\end{array}$ & 4,43 & 0,73 \\
$\mathbf{7} \begin{array}{l}\text { Após minha participação no EMPRETEC, passei a ter uma visão mais } \\
\text { destemida do futuro (olhar para o futuro sem medo e com mais clareza). }\end{array}$ & 4,19 & 0,90 \\
$\mathbf{8} \begin{array}{l}\text { O EMPRETEC tornou-me mais receptivo a mudanças na empresa e/ou no } \\
\text { trabalho. }\end{array}$ & 4,06 & 0,86 \\
\hline
\end{tabular}

Fonte: Dados da pesquisa (2019).

É possível inferir também, que os empretecos conseguiram se relacionar melhor com sócios, funcionários e/ou colegas de trabalho, e também conseguiram repassar a eles algumas novas habilidades adquiridas no seminário, incentivando os funcionários a obter mais conhecimento e experiência passando a investir em novos treinamentos para eles, conforme é apresentado na Tabela 5.

Tabela 5: Média Geral por respostas - itens 9, 10 e 13.

\begin{tabular}{clcc}
\hline $\mathbf{N}^{\mathbf{0}}$ & \multicolumn{1}{c}{ Item } & Média & DP \\
$\mathbf{9}$ & $\begin{array}{l}\text { Meus sócios, funcionários e/ou colegas de trabalho aprenderam comigo } \\
\text { algumas novas habilidades adquiridas no EMPRETEC. }\end{array}$ & 3,55 & 1,01 \\
$\mathbf{1 0}$ & $\begin{array}{l}\text { O EMPRETEC contribuiu para a melhoria no meu relacionamento com sócios, } \\
\text { funcionários e /ou colegas de trabalho. }\end{array}$ & 3,81 & 0,89 \\
$\mathbf{1 3}$ & Investi em treinamento para mim e/ou funcionários após o Empretec. & 3,73 & 1,04 \\
\hline
\end{tabular}
Fonte: Dados da pesquisa (2019).

Os resultados mostram ainda, que os respondentes passaram a acreditar mais em sua capacidade de obter sucesso depois de aplicar as aprendizagens do Empretec e isso os ajudou a melhorar a imagem pessoal e seu potencial de realização, conforme resultados apresentados na Tabela 6 a seguir. 
Tabela 6: Média Geral por respostas - Itens 11 e 12.

\begin{tabular}{cccc}
\hline $\mathbf{N}^{\mathbf{0}}$ & \multicolumn{1}{c}{ Item } & Média & DP \\
$\mathbf{1 1}$ & $\begin{array}{l}\text { Minha participação no EMPRETEC melhorou a imagem que tenho de mim } \\
\text { mesmo e de meu potencial de realização. }\end{array}$ & 4,21 & 0,74 \\
$\mathbf{1 2}$ & $\begin{array}{l}\text { Após o EMPRETEC passei a acreditar mais na minha capacidade de obter } \\
\text { sucesso ao aplicar as novas aprendizagens. }\end{array}$ & 4,19 & 0,90 \\
\hline
\end{tabular}

Fonte: Dados da pesquisa (2019).

Para McClelland (1961), a motivação de realização estaria fortemente relacionada ao comportamento empreendedor e, quanto maior o grau de necessidade de realização de um povo, maior seria o número de indivíduos dotados de competências empreendedoras.

No que diz respeito ao planejamento, os respondentes têm elaborado Plano de Negócio e, com um melhor planejamento, eles conseguiram reduzir os custos gerais da empresa, aumentar o volume de vendas e das receitas após a participação no Empretec. Isso permitiu que eles investissem mais e expandissem seus negócios, conforme Tabela 7 a seguir.

Os resultados apresentados corroboram com os apresentados na pesquisa de Gomes (2014) que mostrou que, dos 49 entrevistados, a maior parte, representando $78 \%$ dos participantes do Empretec na cidade de Angra dos Reis, afirmaram que os resultados financeiros melhoraram.

\section{Tabela 7: Média Geral por respostas - Itens 11 e 12.}

\begin{tabular}{llcc}
\hline $\mathbf{N}^{\mathbf{0}}$ & \multicolumn{1}{c}{ Item } & Média & DP \\
$\mathbf{1 4}$ & Houve redução nos custos gerais da empresa após minha participação no Empretec. & 3,49 & 0,89 \\
$\mathbf{1 5}$ & Passei a elaborar o Plano de Negócio da empresa depois do que aprendi no & 3,28 & 1,10 \\
& Empretec. & 3,50 & 1,32 \\
$\mathbf{1 6}$ & Expandi meu negócio após o Empretec. & 3,56 & 1,22 \\
$\mathbf{1 7}$ & O volume de vendas aumentou após o Empretec. & 3,54 & 1,20 \\
\hline
\end{tabular}

Fonte: dados da pesquisa (2019).

Conforme é mostrado na Tabela 8 a seguir, buscou-se verificar se os empretecos empregaram mais funcionários ou se passaram a empregar menos funcionários por terem conseguido melhorar a eficiência produtiva da empresa. As médias indicam um resultado positivo para o emprego de mais funcionários, já que muitos dos respondentes afirmaram ter expandido seus negócios. Aqueles que passaram a empregar menos funcionários o fizeram por ter conseguido um nível melhor de eficiência em seus processos e otimização dos custos, após ter aplicado o que aprenderam a partir do Empretec.

Tabela 8: Média Geral por respostas - Itens 19 e 20.

\begin{tabular}{llcc}
$\mathbf{N}^{\mathbf{0}}$ & \multicolumn{1}{c}{ Item } & Média & DP \\
$\mathbf{1 9}$ & Após o Empretec empreguei mais funcionários. & 3,20 & 1,36 \\
$\mathbf{2 0}$ & $\begin{array}{l}\text { Após o Empretec empreguei menos funcionários por ter melhorado a eficiência } \\
\text { produtiva da empresa. }\end{array}$ & 2,84 & 1,38 \\
\hline
\end{tabular}

Fonte: Dados da pesquisa (2019).

Por fim, foi observado que não houve consequências até o momento após a participação no Empretec. Esse item apresentou uma média reduzida $(1,75)$ indicando que os empretecos, em sua grande maioria aplicam os recursos aprendidos e reconhecem que o seminário trouxe as melhorias propostas. 


\section{CONSIDERAÇÕES FINAIS}

O número de empreendedores está cada vez maior e se faz cada vez mais necessário o domínio das competências relacionadas ao seu perfil, considerando que, para sua manutenção no mercado, é preciso se adaptar rapidamente às transformações ocorridas. Suas percepções, conhecimentos e ações o ajudam a desenvolver respostas eficazes diante dessas mudanças e contribuem para seu sucesso, fazendo com que se posicionem de forma mais competitiva. Desta forma, é possível identificar as características comportamentais do empreendedor (SANTOS, 2018).

Atendendo ao primeiro objetivo desta pesquisa, foram avaliadas as competências empreendedoras dos empretecos com base no questionário desenvolvido por Alvim (2008) a partir das dez competências empreendedoras de McClelland (1961). A avaliação do desempenho profissional contou com afirmativas que exigiam duas respostas, uma considerando o momento anterior e outra para o momento posterior ao Empretec. Com a avaliação do momento anterior, não foi possível evidenciar que os empresários possuíam as competências empreendedoras indicadas por McClelland (1987). Já na avaliação do momento posterior ao Empretec, evidenciou-se o impacto do treinamento sobre o desempenho profissional do participante, conforme a análise das médias obtidas.

Essa análise do momento posterior à participação no treinamento mostrou também, que o conjunto de realização obteve os maiores resultados em relação às médias conseguidas. Isso significa dizer que, segundo Gomes; Lima e Cappelle (2013), os empreendedores passaram a ter sua motivação baseada na realização, que é o fundamento para o desenvolvimento das demais características que o torna empreendedor, cuja qual, segundo McClelland (1982), foi a base para o desenvolvimento da metodologia utilizada no Empretec.

O segundo objetivo da presente pesquisa diz respeito à avaliação do desempenho organizacional das empresas dos participantes, em relação às aprendizagens conseguidas no seminário. Os resultados evidenciaram que os participantes conseguiram aplicar os conhecimentos aprendidos no treinamento bem como, utilizar estratégias de persuasão, para convencer seus grupos de interesse; estratégias de planejamento e otimização dos recursos para melhores resultados financeiros e operacionais e expansão do negócio.

Assim sendo, é imprescindível a identificação das competências dos empreendedores e dos gestores dos micro e pequenos negócios, o que possibilita reconhecer e fortalecer competências menos desenvolvidas e aprimorar aquelas já desenvolvidas, criando novas oportunidades para o fomento do desenvolvimento da organização (SANTOS, 2018). Desta forma, os resultados obtidos nesta pesquisa tornam evidente o impacto do Empretec sobre o aperfeiçoamento do perfil profissional em relação às competências empreendedoras desenvolvidas no treinamento Empretec e, sobre o desempenho dos negócios dos participantes na cidade de Itabaiana, SE.

\section{REFERÊNCIAS}

ALVIM, S. P. Impacto em profundidade e amplitude: avaliando um treinamento extra organizacional com foco em empreendedorismo. 2018. Dissertação (Pós-graduação em Psicologia) - Universidade Federal da Bahia, Bahia, 2008. 
BARLACH L. Comportamento empreendedor: um estudo empírico baseado no referencial de McClelland. Revista de Carreiras e Pessoas São Paulo. PUC - São Paulo, (FEAUSP), 2014. Volume IV - n. 03. p. 272-281.

BEHLING, G. A. A relação entre as competências empreendedoras e o comportamento estratégico dos microempreendedores individuais (MEI) tomadores de credito de Santa Catarina. 2015. Dissertação (Mestrado em Administração). Universidade Vale do Itajaí. Biguaçu - SC. 2015.

CLEMENTE F. A. S., ALMEIDA P. M. de. Estratégias de Posicionamento e

Características Comportamentais Empreendedoras: Um Estudo de Caso de uma Empresa do Segmento de Comércio Varejista de Eletrodomésticos no Interior de MG. Teoria e Prática em Administração, v. 3 n. 1, 2013, pp. 121-151.

COELHO, F. J. M.; LOUREIRO, A. P. F.; MARQUES, C. S. E. Avaliação do Programa

Empretec: perspectiva quantitativa dos empretecos. Afluente, UFMA/Campus III, 2018. v. 3, n3 7, p. 108-127. ISSN 2525-3441.

COSTA, R. A. T. A importância do treinamento empresarial para a formação de empreendedores: um estudo com base no EMPRETEC - AMAPÁ. Estação Científica (UNIFAP). Macapá, jan./jun. 2015. v. 5, n. 1, p. 69-83.

DOLABELA, F. C. O segredo de Luísa. São Paulo: Cultura Editores Associados, 1999. FONSECA, G. C.; MUYLDER C. F. de. Autopercepção do perfil McClelland: um estudo de caso Empretec Manhuaçu. Revista Ciências Sociais em Perspectiva, $1^{\circ}$ Semestre de 2010. Manhuaçu/MG. ISSN: 1981-4747 (eletrônica) - 1677-9665 (impressa). Vol. 9 - No 16. GIL, A. C. Como elaborar projetos de pesquisa. 5. ed. São Paulo: Atlas, 2010. GOMES J. S. O empreendedorismo: uma análise sobre o perfil do novo empreendedor e os resultados de sua gestão. Revista EDUC - Faculdade de Duque de Caxias, jan.-jun. 2014. vol. 01, p. 55-64, $\mathrm{N}^{\mathrm{o}} 01$.

GOMES, A. F.; LIMA, J. B. de; CAPELLE, M. C. A. Do empreendedorismo à noção de ações empreendedoras: reflexões teóricas. Revista Alcance - Eletrônica, abr./jun. 2013. vol. 20 - n. 02 - p. 203-220.

HEYNS, R. W., VEROFF, J., ATKINSON, J. W. A scoring manual for the affiliation motive. In J. W. Atkinson (Org.), Motives in fantasy, action and Society. pp. 205-218. Princeton, New Jersey: Van Nostrand, 1958.

KRÜGER, C.; PINHEIRO J. P.; MINELLO, I. F. As características comportamentais de David McClelland. Revista Caribenha de Ciências Sociais. Universidade Federal de Santa Maria, 2017. ISSN: 2254-7630. P. 1-6.

LORENTZ, M. H. N. O comportamento Empreendedor de diretores da UFSM e sua percepção quanto à universidade empreendedora. 2015. Dissertação (Mestrado em Gestão de Organizações Públicas) - Universidade Federal de Santa Maria, Santa Maria, RS, 2015. MCCLELLAND, D. C. A sociedade competitiva: realização e progresso social. Rio de Janeiro: Expressão e Cultura, 1972.

MANSFIELD, R. S.; MCCLELLAND, D. C.; SPENCER, J. L. M.; SANTIAGO, J. The identification and assessment of competencies and other personal characteristics of entrepreneurs in developing countries. McBer and Compay. Massachusetts. 1987. MCCLELLAND, D. C. American Psychologist, Vol 40 (7), p 812-825, 1985. MCCLELLAND, D. C. Human motivation. Cambridge: Cambridge University Press, 1987. MCCLELLAND, D. C. The Achieving Society. New York: D. Van Nostrand, 1961. MCCLELLAND, D. C. The Achieving Society. New York: Free Press, 1967. 
MCCLELlAND, D. C., ATKINSON, J. W., CLARK, R. A., \& LOWELL, E. L. The achievement motive. East Norwalk, Connecticut: Appleton-Century-Crofts, 1953. MCCLELLAND, D.C. Estudio de la Motivacion Humana. Madrid: Narcea, 1982. MELO, N. M. Sebrae e empreendedorismo: origem e desenvolvimento. 2008. Dissertação (Pós-graduação em Ciências Sociais). Universidade de São Carlos, São Paulo, 2008. MONTEIRO, M. J. V. Efeito do empreendedorismo no desemprego em Portugal. Dissertação (Mestrado em Economia) - Universidade Trás-os-Montes e Alto, Vila Real, 2014.

MORALES, S. Relação entre competências e tipos psicológicos junguianos entre empreendedores. 2004. Tese (Doutorado em Engenharia de Produção) - Universidade Federal de Santa Catarina, Florianópolis, 2004.

MURRAY, H. A. Explorations in personality. Nova York: Oxford University Press, 1938. SANTOS, G. S. Comportamento estratégico e competências empreendedoras: um estudo de sua relação a partir da percepção dos gestores de micro e pequenas empresas no agreste do estado do Sergipe. 2018. Monografia (Bacharelado em Administração) - Universidade Federal de Sergipe, Itabaiana, 2018.

SEBRAE. Empretec: 25 anos no Brasil e 17 anos em Sergipe. Disponível em:

http://www.sebrae.com.br/sites/PortalSebrae/ufs/se/artigos/artigo-empretec-25-anos-no-brasile-17-anos-em-sergipe, af1a08f2808c7610VgnVCM1000004c00210aRCRD. Acesso em 05 ago. 2018.

SEBRAE. Panorama dos Pequenos Negócios. Disponível em:

http://www.sebrae.com.br/Sebrae/Portal\%20Sebrae/UFs/SP/Pesquisas/Panorama_dos_Pequen os_Negocios_2018_AF.pdf. Acesso em: 20 jan. 2019.

SEBRAE. Revista Eletrônica Conexão Sebrae ano VII, Nº 38, set-out 2013. Disponível em:

http://www.sebrae.com.br/Sebrae/Portal\%20Sebrae/UFs/SP/Not\%C3\%ADcias/Revista\%20C onex\%C3\%A3o/conexao_38. Acesso em 15 nov. 2018.

SEBRAE. Seminário Empretec. 2018. Disponível em:

http://www.sebrae.com.br/sites/PortalSebrae/ufs/es/cursos_eventos/participe-do-seminarioempretec-no-es,bf1088c5275a0510VgnVCM1000004c00210aRCRD. Acesso em: 21 nov. 18. TORRES, R. S. Estudo de Impacto do Programa de Treinamento Comportamental em Empreendedorismo - EMPRETEC. 2018. Dissertação (Mestrado em Empreendedorismo). São Paulo, 2018.

UNCTAD. Boletim N. 34. 2018. Disponível em: http://empretec.unctad.org/?page_id=318. Acesso em: 14 dez. 2018.

VEROFF, J. A scoring manual for the power motive. 1992. In J. W. Atkinson (Org.), motives in fantasy, action and Society. Princeton: Van Nostrand, 1992. pp. 219-233.

VEROFF, J. Power motivation. 1992. In Charles P. Smith (Ed.), Motivation and personality: Handbook of thematic content analysis. Cambridge: Cambridge University Press. pp. 278285, 1992.

WINTER, D. J. Motivating economic achievement. New York: Free Press, 1971. 